\title{
A NEW SPECIES AND A NEW RECORD OF THE GENUS AUSTRalomyMaR GIRAULT (HYMENOPTERA: MYMARIDAE) FROM THE ORIENTAL REGION
}

\author{
T.C. Narendran ${ }^{1}$, Mohammad Hayat ${ }^{2}$ and P.A. Sinu ${ }^{3}$ \\ ${ }^{1}$ Systematic Entomology Laboratory, Department of Zoology, University of Calicut, Tenjipalam, Kerala 673635, India. \\ ${ }^{2}$ Department of Zoology, Aligarh Muslim University, Aligarh,Uttar Pradesh 202002, India. \\ ${ }^{3}$ Ashoka Trust for Research in Ecology and Environment (ATREE), No. 659, $5^{\text {th }}$ A, Main Road, Hebbal, Bangalore, Karnataka 560024, India \\ ${ }^{I}$ Email: drtcnarendran@yahoo.com
}

\begin{abstract}
A new species of the genus Australomymar Girault is described from Oriental region and its affinities are discussed.
\end{abstract}

Keywords

Hymenoptera, Mymaridae, Australomymar, new species, Oriental Region

\begin{tabular}{lr}
\multicolumn{1}{c}{ Abbreviations } \\
DZUC - Department of Zoology, University of Calicut & F1-F6 - Funicular segments 1-6 \\
OOL - Ocellocular distance & POL - Post ocellar distance
\end{tabular}

\section{Introduction}

The genus Australomymar was raised by Girault in 1929 on the type species Australomymar aurigerum from Victoria, Australia. New (1974) redesribed the genus since the original description of Girault was inadequate for its easy recognition. Noyes and Valentine (1989) noted that there are several undescribed species of Australomymar in New Zealand, Neotropical region and in various parts of South East Asia. In this paper we describe a new species from India.

\section{Australomymar formosum Narendran \& Hayat sp. nov.}

(Figs. 1-4)

\section{Material examined}

Holotype: Female on card, 17.ix.2001, Sringeri, Karnataka, India, Cholarm, coll. P.A. Sinu, DZUC MYR-1-T.C.N.

\section{Etymology}

The species name is Latin for beautiful.

\section{Diagnostic features}

Female: Length $1.37 \mathrm{~mm}+$ ovipositor length $1.52 \mathrm{~mm}$. Head and metasoma dark brown; mesosoma pale brown with propodeum slightly darker; eye dull yellowish-brown with yellowish reflecting spots; ocelli dark brown; antenna pale yellowishbrown with clava, scape and radicula paler; legs pale yellow, ovipositor and ovipositor sheath pale brown; wings hyaline with slight brownish tinge with an oblique median pale streak on forewing.

Head: Non-collapsing; width in anterior view $1.27 \mathrm{x}$ its median length, width in dorsal view about $2.1 \mathrm{x}$ its median length; frons with a deep cross groove connected to adorbital carinae (Fig. 2); frons distinctly reticulate, toruli nearer to eyes than to each other; eyes without hairs, ommatidia distinctly demarcated; vertex lightly reticulate; POL 1.5x OOL; occipital margin sharp; malar sulcus relatively short (Fig. 1); malar space one-fifth diameter of eye in profile; clypeus delimited; toruli closer to eye border than to each other; a group of four forwardly directed setae present between bases of toruli; face with three or four setae on either side on ventral part. Antennal formula 11061. Relative lengths of antennal segments: radicula- 8.5 ; scape-20; pedicel-4; F1-9; F2-11, F3-9, F4-9, F5-8, F6-6, clava-12; clava with an area of granular sensillae beneath, without the longitudinal sensoriae at apex.

Mesosoma: Moderately reticulate on most parts of dorsum; mesoscutum with two pairs of setae anteriorly, one pair 

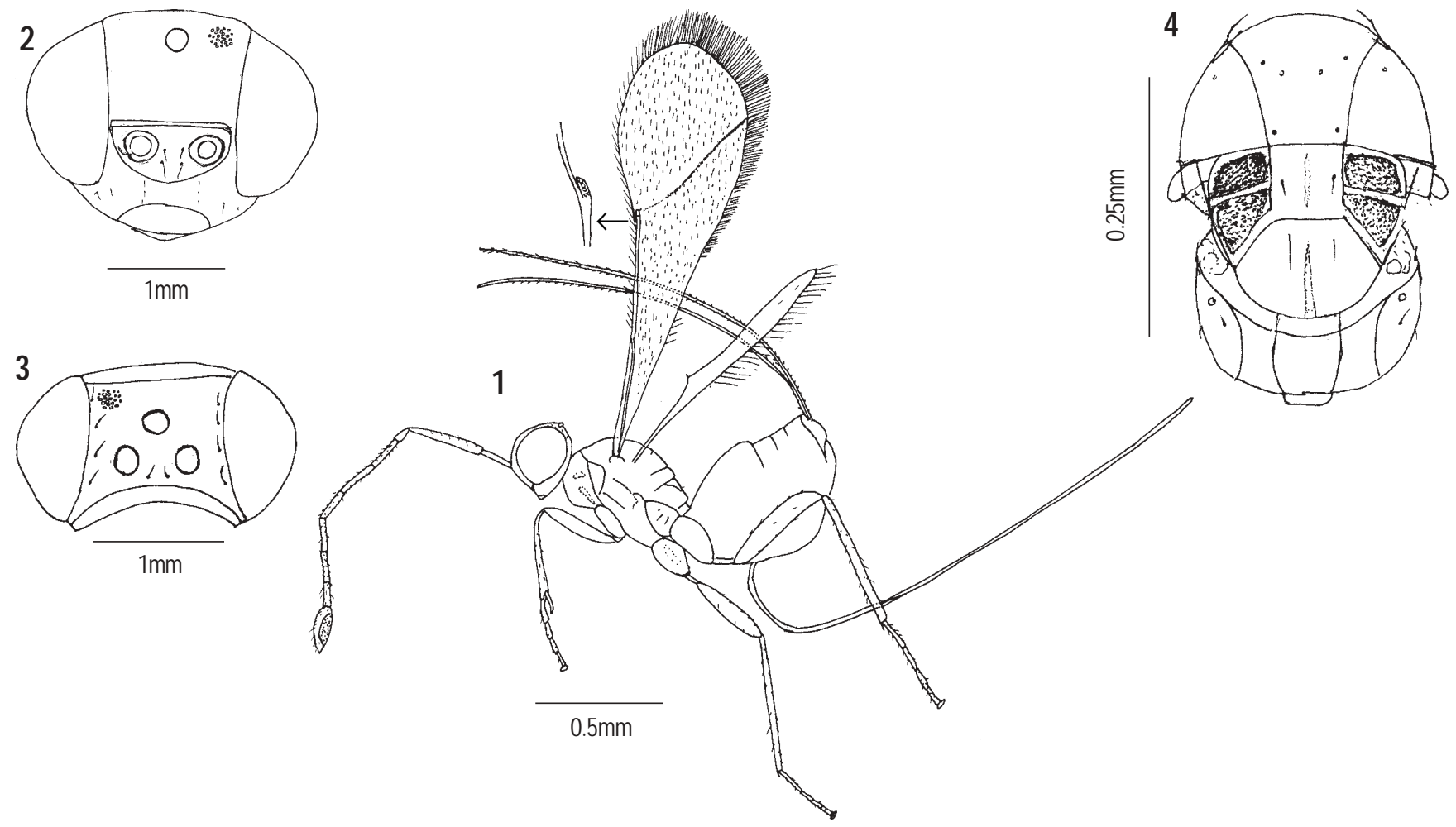

Figures 1-4. Australomymar formosum Narendran \& Hayat sp. nov. (Female) 1 - Body profile; 2 - head front view; 3 - Head dorsal view; 4 - Mesosoma dorsal view

posteriorly; scapula with a seta anteriorly; scutellum with a pair of setae; postscutellum longer than scutellum, with a median sulcus appearing to divide it into two separate plates posteriorly; legs as in Fig. 1; fore tibial spur relatively longer than those of mid tibia and hind tibia; each leg with four tarsal segments. Forewing (Fig. 1) length (without considering length of fringe) about $3.4 \mathrm{x}$ its maximum width; with an oblique light black streak of colour running from stigmal vein to anal margin; stigmal vein with five sensillae; marginal vein of forewing relatively longer than in most mymarids, extending well beyond half of forewing (Fig. 1); maximum width of marginal fringe about $0.1 \mathrm{x}$ length of forewing.

Metasoma: Sessile, length (excluding ovipositor sheath) half of gaster; all tergites mostly smooth with faint reticulations; ovipositor sheath longer than body.

\section{Discussion}

This new species differs from the only known species Australomymar aurigerum Girault in having: (1) ovipositor sheath $2.4 \mathrm{x}$ as long as mesosoma (distinctly less than $2 \mathrm{x}$ length of mesosoma in aurigerum); (2) clava $2 \mathrm{x}$ as long as preceding segment (clava slightly less than $4 \mathrm{x}$ as long as preceding segment in aurigerum); (3) clava with an area of granular microsensillae and without longitudinal sensoriae (in aurigerum with such sensoriae, but without granular microsensillae); (4) hind tibia without conspicuous hairs on outer margin (with conspicuous hairs on outer margin of hind tibia in aurigerum); Forewing vein distinctly exceeding half of wing (in aurigerum only slightly exceeding half of wing).

\section{Acknowledgements}

TCN is grateful to the authorities of the University of Calicut and $\mathrm{MH}$ is grateful to the Aligarh Muslim University for facilities. PAS is grateful to Dr. Dharmarajan Priyadarshan of ATREE, Bangalore for support in his research.

\section{References}

Girault, A.A. (1929). Notes on and descriptions of Chalcid wasps in the South Australian Museum. Concluding paper. Transactions of Royal Society of South Australia 53: 309-346.

New, T.R. (1974). The relationship of the genus Australomymar (Hymenoptera: Mymaridae). Entomophaga 19(3): 229-235.

Noyes, J.S. and E.W. Valentine (1989). Mymaridae (Insecta: Hymenoptera) introduction and review of genera. Fauna of New Zealand 17: 1-95. 